\title{
Identifying Patients With a Higher Potential for Recovery Post Left Ventricular Assist Device: A Single-Center Experience
}

\author{
Arslan Mirza, MD, ${ }^{1}$ Carlos Manuel Romero, MD, ${ }^{2}$ Yoshiya Toyoda, MD, PhD, ${ }^{1}$ Eman A. Hamad, MD ${ }^{1}$ \\ ${ }^{1}$ Temple Heart and Vascular Institute, Temple University Hospital, Philadelphia, PA ${ }^{2}$ Department of Internal Medicine, Temple University \\ Hospital, Philadelphia, PA
}

Background: Few patients with a left ventricular assist device (LVAD) achieve functional myocardial recovery to the point of LVAD explantation. The aim of this study was to highlight some of the hemodynamic and echocardiographic parameters we observed in patients who recovered.

Methods: We conducted a retrospective analysis of 7 patients who received the HeartMate II LVAD (Abbott) at Temple Heart and Vascular Institute and subsequently underwent successful explantation following myocardial recovery. We compared baseline characteristics, echocardiographic data, and hemodynamic data.

Results: Baseline characteristics of the cohort were as follows: age $51.6 \pm 12.0$ years, $57.1 \%$ male, $42.9 \%$ with nonischemic cardiomyopathy, and mean duration of LVAD support of 10.6 months. Comparison of echocardiographic and hemodynamic data (preimplant vs preexplant) revealed the following: left ventricular ejection fraction (\%) was $12.8 \pm 6.9$ vs $52.8 \pm 8.1$ ( $P=0.0001)$, right atrial pressure $(\mathrm{mmHg})$ was $12.3 \pm 3.4 \mathrm{vs} 5.0 \pm 4.0(P=0.022)$, mean pulmonary artery pressure $(\mathrm{mmHg})$ was $36.0 \pm 7.8$ vs 15.4 $\pm 7.1(P=0.01)$, cardiac output $(\mathrm{L} / \mathrm{min})$ was $3.6 \pm 1.3$ vs $5.5 \pm 1.8(P=0.004)$, and cardiac index $\left(\mathrm{L} / \mathrm{min} / \mathrm{m}^{2}\right)$ was $1.8 \pm 0.5 \mathrm{vs} 2.7 \pm 0.7$ $(P=0.008)$. Mean LVAD-free survival was 49.1 months. Results were consistent in both ischemic and nonischemic LVAD explants. Conclusion: A potential for LVAD explantation exists in patients with both ischemic and nonischemic cardiomyopathy. Myocardial recovery may be more likely among young patients with nonischemic cardiomyopathy and patients with recently diagnosed ischemic cardiomyopathy. Future prospective studies are needed.

Keywords: Adult, cardiomyopathies, circulatory support devices, heart failure, myocardial remodeling

Address correspondence to Eman A. Hamad, MD, Temple Heart and Vascular Institute, Temple University Hospital, 3401 N Broad St., Parkinson Pavilion, 9th Floor, Philadelphia, PA 19140. Tel: (267) 908-0210. Email: eman.hamad@tuhs.temple.edu

\section{INTRODUCTION}

Heart failure affects nearly 6 million Americans, ${ }^{1}$ is the leading cause of death globally for both men and women, and contributes to approximately 0.3 million deaths per year. An estimated 200,000 patients with advanced heart failure can benefit from advanced heart failure therapies. ${ }^{2}$ Heart transplant is the gold standard for advanced heart failure, but because of the limited number of donor organs, left ventricular assist device (LVAD) therapy plays a major role as a bridge to transplant as well as destination therapy for patients who are not candidates for transplant. Despite great improvement in its design and adverse event profile, LVAD therapy is still limited by many complications such as gastrointestinal bleed, device thrombosis, infection, and device malfunction. ${ }^{3}$ Heart transplant is also associated with complications: a lifelong need for immunosuppression to prevent cardiac allograft rejection, risk of infection, vasculopathy, and organ dysfunction. ${ }^{4}$ Together, these limitations have stimulated research into the feasibility of LVADs as a bridge to structural remodeling and recovery.

Among patients undergoing LVAD implantation, $<2 \%$ achieve functional myocardial recovery to the point of eventual LVAD explantation. ${ }^{5}$ Numerous investigatorseither at single centers or in multi-institutional working groups - have reported successful cases of LVAD removal ${ }^{6}$ and have shared their experiences, including ways to approach patients who may be suitable candidates for LVAD explantation. ${ }^{7,8}$ However, no specific guidelines for LVAD weaning or criteria for explantation exist. ${ }^{5}$ The purpose of our study was to share our experience with recovery and device explantation and list markers that may aid others in predicting the potential for explant.

\section{METHODS}

We conducted a retrospective medical record review of patients admitted to Temple Heart and Vascular Institute 
between January 2011 and December 2019 who were no longer LVAD dependent. Prior to the start of our study, the Temple Institutional Review Board (IRB) evaluated and approved our protocol and methods. The Temple IRB determined that all the criteria for a waiver of Health Insurance Portability and Accountability Act authorization were met.

As part of our institution's protocol, all patients received a right heart catheterization and transthoracic echocardiogram prior to their LVAD implant. Following LVAD support, patients' heart failure regimens were optimized using beta blockers, angiotensin-converting enzyme inhibitors or angiotensin receptor blockers, nitrates/hydralazine, and potassium-sparing diuretics when able. Serial echocardiograms and 6-minute walk tests were obtained on all patients at 1 month, followed by 3- to 6-month intervals thereafter as part of routine surveillance.

\section{Weaning Protocol}

Patients showing echocardiographic signs of recovery on routine surveillance were first assessed for explant potential by slightly reducing their LVAD speeds. In the majority of cases, LVAD speeds were reduced in the inpatient setting when patients were not in acute decompensated heart failure. Initial LVAD speeds were not reduced below 8,600 revolutions per minute (rpm). If patients remained asymptomatic at the reduced LVAD speeds, they were then closely followed in the office for worsening symptoms and with surveillance echocardiograms.

Asymptomatic patients with persistent echocardiographic signs of significant recovery-defined as left ventricular ejection fraction (LVEF) $>40 \%$ - were scheduled for further functional assessment testing using the 6-minute walk test, cardiopulmonary exercise test when able, and an elective weaning study at the cardiac catheterization lab. During a turndown study in the catheterization lab, invasive hemodynamic and echocardiographic parameters were recorded as LVAD speed was slowly turned down by 400 to $500 \mathrm{rpm}$ every 5 to 10 minutes. The speed was reduced to as low as $7,000 \mathrm{rpm}$ before returning it to baseline. The final decision to explant in all cases was done after a multidisciplinary heart failure team evaluation.

Ten patients who were no longer LVAD dependent were initially selected for the study. However, the final analysis included 7 patients who received the HeartMate II LVAD (Abbott) and exhibited significant functional myocardial recovery (LVEF $>40 \%$ ), resulting in successful explant.

Among those excluded, one patient had incomplete recovery (LVEF $<40 \%$ ) but was no longer LVAD dependent because of pump stoppage from driveline fracture. One patient refused explant despite complete recovery. One patient showed signs of initial recovery and had a successful weaning study in the cardiac catheterization lab; however, when taken to the operating room for explant, the patient did not tolerate and failed the final wean.

Data entry and analysis were carried out using SPSS statistical software, version 27 (IBM Corp) and Excel (Microsoft Corp). Paired sample $t$ test was used to compare preimplant and preexplant echocardiographic and hemodynamic parameters.

\section{RESULTS}

Table 1 shows basic demographics and outcomes of patients who underwent HeartMate II explant following recovery. Mean age at the time of implant was $51.6 \pm 12.0$ years. All patients in our study had stage $D$ heart failure as evidenced by their need for inotropic support, shortterm mechanical circulatory support, or both prior to LVAD implantation. Three of the patients had ischemic cardiomyopathy. Mean duration of LVAD support was 10.6 months. The mean LVAD-free survival following explant was 49.1 months. Death occurred in 2 patients after a mean LVAD-free survival of 12 months.

\section{Improvement in Echocardiographic Parameters}

Table 2 shows the difference between preimplant and preexplant echocardiographic parameters in patients with LVAD recovery. We observed a significant improvement in echocardiographic parameters, including LVEF (preimplant $12.8 \% \pm 6.9 \%$ vs preexplant $52.8 \% \pm 8.1 \%, P=0.0001$ ), left ventricular end-diastolic internal diameter (preimplant $60.4 \mathrm{~mm} \pm 11.7 \mathrm{~mm}$ vs preexplant $42.6 \mathrm{~mm} \pm 5.7 \mathrm{~mm}$, $P=0.02)$, and right ventricle diastolic dimensions.

\section{Improvement in Hemodynamic Parameters}

Table 3 shows the difference in preimplant and preexplant hemodynamic parameters among patients with LVAD recovery. We observed a significant improvement in right atrial pressure (preimplant $12.3 \mathrm{mmHg} \pm 3.4 \mathrm{mmHg}$ vs preexplant $5.0 \mathrm{mmHg} \pm 4.0 \mathrm{mmHg}, P=0.022$ ), mean pulmonary artery pressure (preimplant $36.0 \mathrm{mmHg} \pm 7.8 \mathrm{mmHg}$ vs preexplant $15.4 \mathrm{mmHg} \pm 7.1 \mathrm{mmHg}, P=0.01$ ), cardiac index (preimplant $1.8 \mathrm{~L} / \mathrm{min} / \mathrm{m}^{2} \pm 0.5 \mathrm{~L} / \mathrm{min} / \mathrm{m}^{2}$ vs preexplant $2.7 \mathrm{~L} / \mathrm{min} / \mathrm{m}^{2}$ $\pm 0.7 \mathrm{~L} / \mathrm{min} / \mathrm{m}^{2}, P=0.008$ ), and cardiac output (preimplant $3.6 \mathrm{~L} / \mathrm{min} \pm 1.3 \mathrm{~L} / \mathrm{min}$ vs preexplant $5.5 \mathrm{~L} / \mathrm{min} \pm 1.8 \mathrm{~L} / \mathrm{min}$, $P=0.004)$.

\section{Improvement in Functional Capacity}

Following explant, patients were noted to have improved functional capacity at 6,12 , and 24 months following explant (Figure).

\section{DISCUSSION}

Our experience with LVAD explant shows that myocardial recovery is possible in patients with both ischemic and nonischemic cardiomyopathy. Although data from LVAD registries show the overall incidence of LVAD explantation to be $<2 \%$, centers with dedicated cardiac recovery programs suggest that the rate of cardiac improvement occurs in approximately $15 \%$ to $25 \%$ of patients with nonischemic cardiomyopathy and in $4 \%$ to $5 \%$ of patients with ischemic cardiomyopathy. ${ }^{9,10}$ Because of the wide array in the etiologies of myocardial disease, speed of recovery, and proportions of patients who recover, the mechanism for myocardial recovery also likely varies. However, myocardial recovery is believed to be related to various genomic, molecular, cellular, structural, and systemic changes ${ }^{11}$ that occur during chronic left ventricular unloading, resulting in regression of cellular hypertrophy - a phenomenon termed reverse cardiac remodeling. ${ }^{12}$ Clinically, cardiac remodeling manifests as improvement in hemodynamic parameters such as cardiac output, mean pulmonary pressures, left ventricular chamber size, LVEF, and organ perfusion. ${ }^{13}$ 


\begin{tabular}{|c|c|c|c|c|c|c|c|}
\hline \multirow[b]{2}{*}{ Variable } & \multicolumn{7}{|c|}{ Patient Number } \\
\hline & $1^{\mathrm{a}}$ & $\mathbf{2}^{\mathrm{a}}$ & 3 & $4^{a}$ & 5 & $6^{a}$ & $7^{a}$ \\
\hline Age, years & 49 & 36 & 67 & 63 & 47 & 60 & 39 \\
\hline Sex & M & M & $\mathrm{F}$ & $F$ & M & M & $\mathrm{F}$ \\
\hline Race & $\mathrm{AA}$ & C & C & $\mathrm{AA}$ & C & AA & C \\
\hline Diabetes mellitus & Yes & - & Yes & - & Yes & Yes & - \\
\hline Coronary artery disease & - & - & - & Yes & Yes & Yes & - \\
\hline Chronic kidney disease & Yes & - & Yes & - & Yes & Yes & - \\
\hline Hypertension & Yes & - & Yes & Yes & Yes & Yes & - \\
\hline Initial heart failure diagnosis, years & $>5$ & $<1$ & $1-5$ & $<1$ & $>5$ & $<1$ & $1-5$ \\
\hline Etiology of cardiomyopathy & Idiopathic & Idiopathic & Idiopathic & Ischemic & Ischemic & Ischemic & Idiopathic \\
\hline Implant indication & DT & DT & DT & DT & DT & DT & DT \\
\hline Preimplant supportive therapy & Tandem & Inotrope, IABP & Inotrope & $\begin{array}{c}\text { Inotrope, emergent } \\
\text { CABG, IABP }\end{array}$ & Inotrope, IABP & Tandem & Inotrope \\
\hline Explant indication & $\begin{array}{c}\text { EF recovery, LVAD } \\
\text { infection }\end{array}$ & EF recovery & EF recovery & $\begin{array}{l}\text { EF recovery, driveline } \\
\text { infection }\end{array}$ & EF recovery & $\begin{array}{c}\text { EF recovery, driveline } \\
\text { infection }\end{array}$ & EF recovery \\
\hline Preimplant EF, \% & 10 & 5 & 10 & 20 & 20 & 20 & 5 \\
\hline Preexplant $\mathrm{EF}, \%$ & 60 & 55 & 60 & 60 & 40 & 50 & 45 \\
\hline Duration of LVAD support, months & 10 & 10 & 12 & 2 & 6 & 8 & 26 \\
\hline LVAD-free survival, months ${ }^{\mathrm{a}}$ & $77+$ & $69+$ & 16 & $86+$ & 13 & $68+$ & $15+$ \\
\hline Complications & - & - & Death & - & $\begin{array}{l}\text { LVAD reimplant, } \\
\text { OHT, death }\end{array}$ & - & - \\
\hline
\end{tabular}

${ }^{a}$ As of the writing of this study.

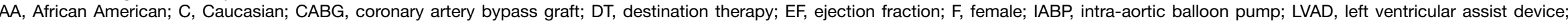

$\mathrm{M}$, male; $\mathrm{OHT}$, orthotopic heart transplant. 
Table 2. Comparison of Preimplant and Preexplant Echocardiographic Parameters, $n=7$

\begin{tabular}{|c|c|c|c|}
\hline Echocardiographic Parameter & Preimplant, Mean \pm SD & Preexplant, Mean \pm SD & $P$ Value \\
\hline Heart rate, min & $91.7 \pm 16.4$ & $69.6 \pm 8.9$ & 0.01 \\
\hline Left ventricular ejection fraction, $\%$ & $12.8 \pm 6.9$ & $52.8 \pm 8.1$ & 0.0001 \\
\hline Left ventricular end-diastolic internal diameter, $\mathrm{mm}$ & $60.4 \pm 11.7$ & $42.6 \pm 5.7$ & 0.02 \\
\hline Left ventricular end-systolic internal diameter, mm & $53.4 \pm 14.3$ & $33.4 \pm 6.2$ & 0.02 \\
\hline Base right ventricular internal diastolic diameter, $\mathrm{mm}$ & $39.5 \pm 6.2$ & $34.8 \pm 5.0$ & 0.045 \\
\hline Mid right ventricular internal diastolic diameter, mm & $24.3 \pm 7.4$ & $18.6 \pm 5.6$ & 0.03 \\
\hline Longitudinal right ventricular internal diastolic diameter, $\mathrm{mm}$ & $77.6 \pm 3.7$ & $68.8 \pm 5.8$ & 0.006 \\
\hline
\end{tabular}

Note: $P<0.05$ is statistically significant.

Table 3. Comparison of Preimplant and Preexplant Hemodynamic Parameters, $\mathbf{n = 7}$

\begin{tabular}{|c|c|c|c|}
\hline Hemodynamic Parameter & Preimplant, Mean \pm SD & Preexplant, Mean \pm SD & P Value \\
\hline Right atrial pressure, $\mathrm{mmHg}$ & $12.3 \pm 3.4$ & $5.0 \pm 4.0$ & 0.022 \\
\hline Right ventricular systolic pressure, $\mathrm{mmHg}$ & $56.5 \pm 10.2$ & $29.2 \pm 11.2$ & 0.067 \\
\hline Right ventricular end-diastolic pressure, $\mathrm{mmHg}$ & $17.3 \pm 2.1$ & $7.6 \pm 5.1$ & 0.176 \\
\hline Pulmonary artery systolic pressure, $\mathrm{mmHg}$ & $54.8 \pm 13.5$ & $30.7 \pm 9.3$ & 0.036 \\
\hline Pulmonary artery diastolic pressure, $\mathrm{mmHg}$ & $27.3 \pm 5.5$ & $8.9 \pm 4.1$ & 0.003 \\
\hline Mean pulmonary artery pressure, $\mathrm{mmHg}$ & $36.0 \pm 7.8$ & $15.4 \pm 7.1$ & 0.01 \\
\hline Pulmonary capillary wedge pressure, $\mathrm{mmHg}$ & $23.3 \pm 6.5$ & $7 \pm 4.3$ & 0.035 \\
\hline Transpulmonary gradient, $\mathrm{mmHg}$ & $11.0 \pm 6.9$ & $9.8 \pm 2.8$ & 0.678 \\
\hline Diastolic pulmonary vascular pressure gradient, $\mathrm{mmHg}$ & $4.0 \pm 3.7$ & $3.2 \pm 4.0$ & 0.862 \\
\hline Cardiac output, L/min & $3.6 \pm 1.3$ & $5.5 \pm 1.8$ & 0.004 \\
\hline Cardiac index, $\mathrm{L} / \mathrm{min} / \mathrm{m}^{2}$ & $1.8 \pm 0.5$ & $2.7 \pm 0.7$ & 0.008 \\
\hline Pulmonary vascular resistance, Wood units & $3.6 \pm 1.5$ & $1.9 \pm 0.5$ & 0.08 \\
\hline Systemic vascular resistance, $\mathrm{dyn} \cdot \mathrm{s} / \mathrm{cm}^{5}$ & $1,725.8 \pm 779.5$ & $1,248.3 \pm 753.9$ & 0.06 \\
\hline
\end{tabular}

Note: $P<0.05$ is statistically significant.

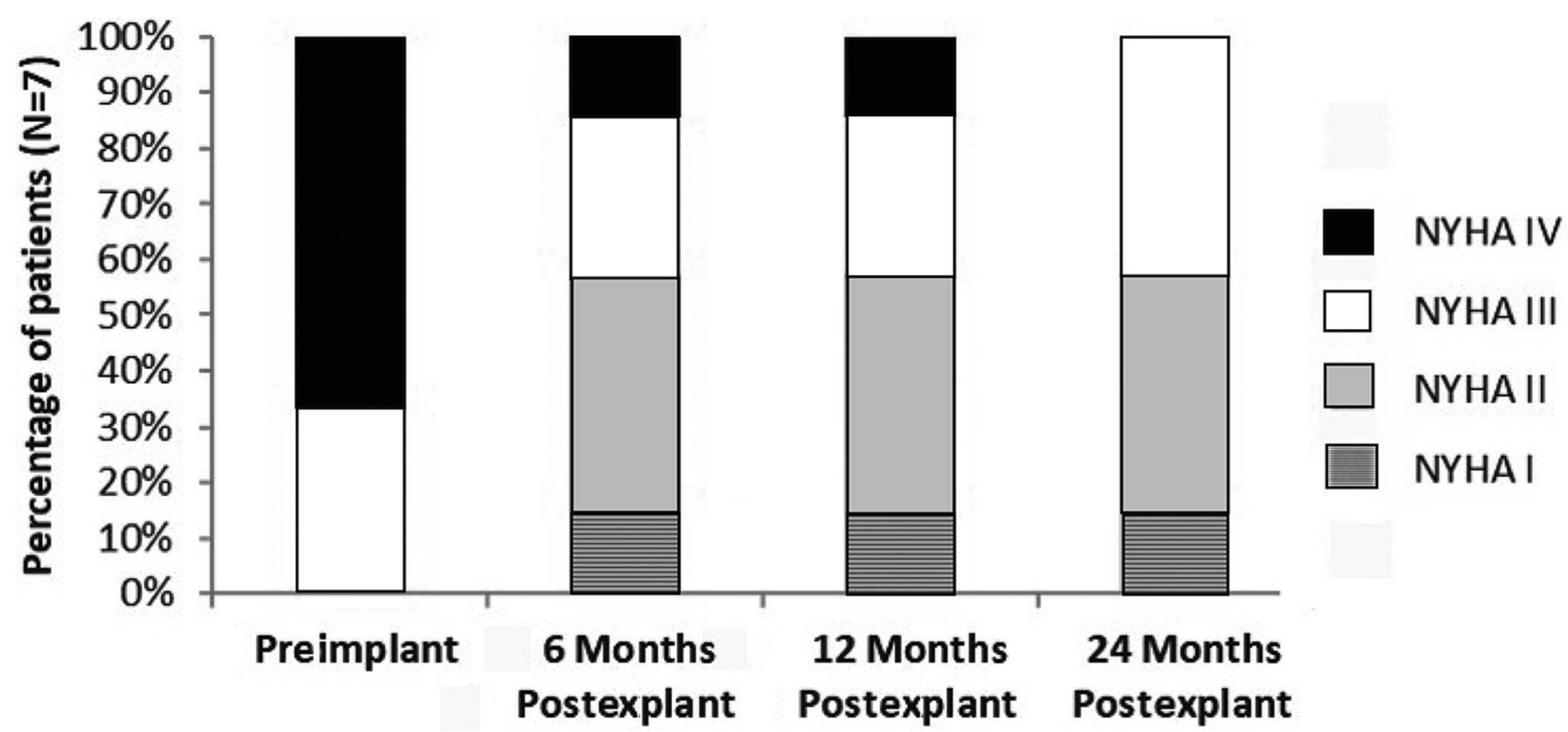

Figure. Trend of New York Heart Association (NYHA) functional class from preimplant to 24 months postexplant, $\mathbf{n = 7 .}$ 
Patients in our series were young and more likely to have nonischemic vs ischemic cardiomyopathy (Table 1). Previous studies have shown that young age is associated not only with a higher likelihood of recovery but also with improved survival outcomes. , $8,14-17$ In most of these studies, the mean age of explanted patients was $<40$ years. ${ }^{18}$ Interestingly, for the patients in our study, the duration of LVAD support prior to explant was longer in nonischemic vs ischemic patients. Thus, given the lack of donor organs, implanted patients who are $<50$ years of age and have nonischemic cardiomyopathy should not be rushed into cardiac transplant because they may achieve explant potential after prolonged LVAD support.

We also observed that all of our implanted patients with recent onset heart failure (initial diagnosis $<1$ year from time of implant) had an LVAD-free survival of $>5$ years following explant (Table 1). Although limited data are available, previous studies have suggested that patients with shorter durations of heart failure have longer LVAD-free survival time than those with longer durations of heart failure. $7,8,15,16,19$

Explantation, however, does not come without risks. Perioperative mortality of explanted patients is close to $9 \%$, and late mortality is approximately $15 \% .{ }^{18}$ However, in patients who are successfully weaned, 5-year freedom from heart failure can reach up to $81 \%$, while survival rates at 1,5 , and 10 years post-LVAD removal have been close to $91 \%, 76 \%$, and $66 \%$, respectively. ${ }^{18}$

All explanted patients at our center showed normalization of echocardiographic and hemodynamic parameters prior to explant (Tables 2 and 3). While the mean LVEF of our explanted population was $>50 \%$, the lowest LVEF in a successfully explanted patient was $40 \%$. Dandel et al showed that a preexplant off-pump LVEF of $\geq 50 \%$ and $\geq 45 \%$ can predict cardiac stability lasting $\geq 5$ years after LVAD removal of $91.7 \%$ and $79.1 \%$, respectively. ${ }^{20}$ With each unit of LVEF reduction, the risk of heart failure recurrence is 1.5 times higher.

Although no uniformly accepted weaning criteria exist for device explantation, previous studies have proposed weaning protocols and recommendations. In the Utah Cardiac Recovery study, cardiac recovery was defined as post-LVAD LVEF $\geq 40 \%$ in $\geq 2$ consecutive turndown echocardiograms and no LVEF $<40 \%$ at later time points (independently from whether the device was eventually explanted). ${ }^{9}$ In contrast, the Berlin study group considered explant to be safe when during repeated off-pump trials performed over several days, the maximum left ventricular end-diastolic diameter was $55 \mathrm{~mm}$, the minimum LVEF was $45 \%$, and the right ventricle size and function remained stable. ${ }^{8}$ Other favorable explant parameters taken into account by prior studies include left ventricular end-diastolic diameter $\leq 55 \mathrm{~mm}$, left ventricular end-diastolic pressure $\leq 8 \mathrm{mmHg}$, cardiac index $>2.4$ to $2.8 \mathrm{~L} / \mathrm{min} / \mathrm{m}^{2}$, pulmonary artery wedge pressure $<13 \mathrm{mmHg}$, venous oxygen maximum $\geq 20 \%$, ventilatory efficiency/ ventilatory carbon dioxide $<34$, brachial artery pressure $\geq 65$ $\mathrm{mmHg}$, and a resting heart rate $<90 / \mathrm{min}^{18}$

With growing evidence toward cardiac recovery using left ventricular unloading, aggressive management of every patient with end stage heart disease with optimum medical therapy is crucial, especially early after implant in hope for myocardial recovery. Because of a limited number of donor organs and long-term complications associated with both
LVADs and transplanted hearts, recovery of the native heart is the most desirable clinical outcome and should be actively sought. The option of transplantation should be used only after recovery of ventricular function has been ruled out. Ruling out recovery prior to transplantation is particularly important in young patients who are unlikely to live a normal lifespan even after a successful heart transplant. ${ }^{18}$

Data from most studies are retrospective with various generations of LVAD devices or include small patient populations, including our study. Future studies should focus on larger prospective populations implanted with the new generation of LVAD devices and should compare various weaning strategies that have been used successfully in the past.

\section{CONCLUSION}

The potential for LVAD explantation exists in patients with both ischemic and nonischemic cardiomyopathy. Future prospective studies are needed to determine the potential of myocardial recovery, especially among young patients with nonischemic cardiomyopathy and patients with recently diagnosed ischemic cardiomyopathy.

\section{ACKNOWLEDGMENTS}

The authors have no financial or proprietary interest in the subject matter of this article.

\section{REFERENCES}

1. Benjamin EJ, Muntner $P$, Alonso A, et al.; American Heart Association Council on Epidemiology and Prevention Statistics Committee and Stroke Statistics Subcommittee. Heart disease and stroke statistics-2019 update: a report from the American Heart Association. Circulation. 2019;139(10):e56-e528. doi: $10.1161 / C I R .0000000000000659$. Erratum in Correction to: heart disease and stroke statistics-2019 update: a report from the American Heart Association. Circulation. 2020;141(2):e33. doi: $10.1161 /$ CIR.0000000000000746

2. Mancini $D$, Colombo PC. Left ventricular assist devices: a rapidly evolving alternative to transplant. J Am Coll Cardiol. 2015;65(23):2542-2555. doi: 10.1016/j.jacc.2015.04.039

3. Jorde UP, Kushwaha SS, Tatooles AJ, et al.; HeartMate II Clinical Investigators. Results of the destination therapy post-Food and Drug Administration approval study with a continuous flow left ventricular assist device: a prospective study using the INTERMACS registry (Interagency Registry for Mechanically Assisted Circulatory Support). J Am Coll Cardiol. 2014;63(17):1751-1757. doi: 10.1016/j.jacc.2014.01.053

4. Birati EY, Rame JE. Post-heart transplant complications. Crit Care Clin. 2014;30(3):629-637. doi: 10.1016/j.ccc.2014.03.005

5. Selzman $\mathrm{CH}$, Madden JL, Healy $\mathrm{AH}$, et al. Bridge to removal: a paradigm shift for left ventricular assist device therapy. Ann Thorac Surg. 2015;99(1):360-367. doi: 10.1016/j.athoracsur.2014.07.061

6. Drakos SG, Kfoury AG, Stehlik J, et al. Bridge to recovery: understanding the disconnect between clinical and biological outcomes. Circulation. 2012;126(2):230-241. doi: 10.1161/CIRCULATIONAHA.111.040261

7. Birks EJ, George RS, Firouzi A, et al. Long-term outcomes of patients bridged to recovery versus patients bridged to transplantation. J Thorac Cardiovasc Surg. 2012;144(1):190-196. doi: 10.1016/j.jtcvs.2012.03.021

8. Dandel M, Weng Y, Siniawski H, Potapov E, Lehmkuhl HB, Hetzer R. Long-term results in patients with idiopathic dilated cardiomyopathy after weaning from left ventricular assist 
devices. Circulation. 2005;112(9 Suppl):I37-145. doi: 10.1161/CIRCULATIONAHA.104.525352

9. Drakos SG, Pagani FD, Lundberg MS, Baldwin JT. Advancing the science of myocardial recovery with mechanical circulatory support: a working group of the National Heart, Lung, and Blood Institute. JACC Basic Trans/ Sci. 2017;2(3):335-340. doi: 10.1016/j.jacbts.2016.12.003

10. Lamarche $Y$, Kearns M, Josan K, et al. Successful weaning and explantation of the Heartmate II left ventricular assist device. Can J Cardiol. 2011;27(3):358-362. doi: 10.1016/j.cjca.2011.01.005

11. Ambardekar AV, Buttrick PM. Reverse remodeling with left ventricular assist devices: a review of clinical, cellular, and molecular effects. Circ Heart Fail. 2011;4(2):224-233. doi: 10.1161/CIRCHEARTFAILURE.110.959684

12. Zafeiridis A, Jeevanandam V, Houser SR, Margulies KB. Regression of cellular hypertrophy after left ventricular assist device support. Circulation. 1998;98(7):656-662. doi: 10.1161/01.cir.98.7.656

13. Miller LW, Pagani FD, Russell SD, et al.; HeartMate II Clinical Investigators. Use of a continuous-flow device in patients awaiting heart transplantation. $N$ Engl $J$ Med. 2007;357(9):885-896. doi: 10.1056/NEJMoa067758

14. Goldstein DJ, Maybaum S, MacGillivray TE, et al.; HeartMate II Clinical Investigators. Young patients with nonischemic cardiomyopathy have higher likelihood of left ventricular recovery during left ventricular assist device support. J Card Fail. 2012;18(5):392-395. doi: 10.1016/j.cardfail.2012.01.020
15. Farrar DJ, Holman WR, McBride LR, et al. Long-term follow-up of Thoratec ventricular assist device bridge-to-recovery patients successfully removed from support after recovery of ventricular function. J Heart Lung Transplant. 2002;21(5):516-521. doi: 10.1016/s1053-2498(01)00408-9

16. Saito S, Toda K, Miyagawa S, et al. Hemodynamic changes during left ventricular assist device-off test correlate with the degree of cardiac fibrosis and predict the outcome after device explantation. J Artif Organs. 2015;18(1):27-34. doi: 10.1007/s10047-014-0802-0

17. Frazier OH, Baldwin ACW, Demirozu ZT, et al. Ventricular reconditioning and pump explantation in patients supported by continuous-flow left ventricular assist devices. J Heart Lung Transplant. 2015;34(6):766-772. doi: 10.1016/j.healun.2014.09.015

18. Phan K, Huo YR, Zhao DF, Yan TD, Tchantchaleishvili V. Ventricular recovery and pump explantation in patients supported by left ventricular assist devices: a systematic review. ASAIO J. 2016;62(3):219-231. doi: 10.1097/MAT.0000000000000328

19. Maybaum S, Mancini D, Xydas S, et al.; LVAD Working Group. Cardiac improvement during mechanical circulatory support: a prospective multicenter study of the LVAD Working Group. Circulation. 2007;115(19):2497-2505. doi: 10.1161/CIRCULATIONAHA.106.633180

20. Dandel $M$, Weng $Y$, Siniawski $H$, et al. Heart failure reversal by ventricular unloading in patients with chronic cardiomyopathy: criteria for weaning from ventricular assist devices. Eur Heart J. 2011;32(9):1148-1160. doi: 10.1093/eurheartj/ehq353

This article meets the Accreditation Council for Graduate Medical Education and the American Board of Medical Specialties Maintenance of Certification competencies for Patient Care, Medical Knowledge, and Practice-Based Learning and Improvement.

(C2021 by the author(s); licensee Ochsner Journal, Ochsner Clinic Foundation, New Orleans, LA. This article is an open (C) access article distributed under the terms and conditions of the Creative Commons Attribution (CC BY) license (creativecommons.org/licenses/by/4.0/legalcode) that permits unrestricted use, distribution, and reproduction in any medium, provided the original author(s) and source are credited. 